Orbis Tertius, vol. XXIV, $\mathrm{n}^{\circ}$ 29, e119, mayo-octubre 2019. ISSN 1851-7811

Universidad Nacional de La Plata

Facultad de Humanidades y Ciencias de la Educación

Centro de Estudios de Teoría y Crítica Literaria

\title{
Mónica Marinone y Gabriela Tineo (coords.). Latinoamérica entre lenguajes y lenguas. Mar del Plata, EUDEM, 2018, 408 páginas
}

Una manera de pensar y leer Latinoamérica, un afán por problematizar y complejizar las interpretaciones de sus expresiones literarias a la luz de los intrincados procesos sociales, políticos y culturales que le dan forma (o que impiden, en realidad, que tenga una forma), ha sido, desde hace años, la consigna que guía la producción crítica y académica de Mónica Marinone y Gabriela Tineo, docentes e investigadoras de la Universidad Nacional de Mar del Plata. Subrayo este punto para comenzar porque el libro Latinoamérica entre lenguajes y lenguas no es una mera recopilación de artículos misceláneos, sino un volumen sumamente cohesivo: todos los investigadores que participan en él comparten un posicionamiento epistemológico común y una forma de concebir y pensar la condición heteróclita y plural de la literatura latinoamericana. Los diferentes estudios que conforman el libro, por tanto, son resultado de un proceso de investigación grupal sostenido en el tiempo y fundamentado en el reconocimiento, la valoración y el estudiode las zonas de contradicción, conflicto, negociación y diálogo en los diversos modos de producción simbólica latinoamericana.

El presente volumen - que se inscribe en la serie inaugurada en 2007 con Grabar lo que se desvanece: Narrativas de la memoria en América Latina (Estanislao Balder), seguido por Viaje y relato en Latinoamérica (2010, Katatay) y Noticias del diluvio: Textos latinoamericanos de las últimas décadas (2013, EUDEM) - continúa sus líneas de investigación, poniendo especial énfasis en el carácter móvil de la matriz cultural latinoamericana, capaz de resignificarse y resemantizarse a lo largo del tiempo, que dota a las expresiones artísticas contemporáneas de una tensión fundacional. Habitantes de un territorio cambiante y fragmentario, carente de relatos cohesivos, esas expresiones constituyen para las autoras un repertorio de prácticas artísticas de gran productividad porque dan cuenta de una "zona de límites múltiples absorbente de cruces, contactos, desplazamientos de rumbos cambiantes e interferencias, porosa, propensa a adaptaciones pluridimensionales" (p. 11), en la cual lenguajes y lenguas (en desglose o ensamble) se traman.

Es esperable, entonces, que, en función de esta manera de pensar lo latinoamericano, también sea del interés de las coordinadoras la exploración de otras zonas —además de las lingüísticas, sociales y culturales - en la cuales se observe esa tensión productiva. Con el fin de detectar resonancias, traslapes, préstamos y resignificaciones, la mayoría de los trabajos estudian las intersecciones de lenguajes artísticos, analizan las derivas provocadas por la convergencia o la colisión de códigos y problematizan la traducción como proceso interlingüístico, de negociación cultural o perturbador de visiones de mundo. Podemos afirmar, por tanto, que las palabras de John Cage, "estoy contra toda distinción entre pintura, música, literatura y las otras artes” (p. 23), constituyen una síntesis acertada de otro de los presupuestos compartidos por quienes participan del libro.

Este posicionamiento respecto de la literatura latinoamericana y la relación entre las diferentes artes atraviesa cada uno de los artículos y estructura el orden del volumen, organizado en una introducción a cargo de las coordinadoras, dos ensayos, de Pablo Montoya y Arcadio Díaz Quiñones —ubicados al inicio y al final- , y cinco secciones temáticas. 
Me gustaría destacar particularmente el primer ensayo porque continúa una práctica "tradicional” en los libros de Marinone y Tineo, incluir como apertura de las reflexiones algún texto que sintetiza la orientación del volumen, ya sea con un relato inédito - como La guagua aérea de Luis Rafael Sánchez en Viaje y relatoo una reflexión críticadel puño de un escritor reconocido - como Noticias del diluvio de Eduardo Lalo, en el libro homónimo. En Notas sobre John Cage y la literatura, Montoya estudia la propuesta de Cage respecto de la unidad de la creación artística, enfatizando no solo su relación con los aspectos lúdicos y renovadores del arte contemporáneo del siglo XX, sino también con el imaginario romántico de la literatura que vio en la experimentación sonora un camino de expresión estética. De este modo, establece vínculos entre relatos de Honoré de Balzac y Ernst T. A. Hoffmann con la poética compositiva de Cage y, entre su práctica musical y poética con el I Ching: El libro de las mutaciones, las prácticas del Tarot y algunos textos de Eric Satie, James Joyce y Henry Thoreau.

A continuación, la primera parte de Latinoamérica entre lenguajes y lenguas incluye dos artículos que trabajan la producción de Xul Solar. Andrea Pagni, en Xul Solar, un traductor en dos escenas de traducción, nos ofrece una exploración de la traducción realizada por el artista al neocriollo (una lengua de su invención) de algunos aforismos del escritor alemán Christian Morgenstern, así como de su traducción inédita del relato de Thomas Mann, Die vertauschtenKöpfe. Por su parte, Sabrina Gil (Imágenes narrativas, palabras visuales y unidad latinoamericana en Xul Solar), quien define a Xul como "un artista interferido, cuya producción incluye y trama pintura, literatura, lingüística, música, astrología y esoterismo" (p. 79), se detiene en la acuarela Nana Watzin (1923), atendiendo a una lectura de interferencias de codificaciones y tendencias de diverso orden (Simbolismo, Esoterismo, Expresionismo, experimentación vanguardista, entre otros) y montajes de lenguajes (en especial pictórico y verbal) y observa en ella el despliegue de elementos de un imaginario latinoamericano prehispáhinco puesto en correlación con una utopía de integración continental.

La segunda parte está compuesta por dos estudios sobre los escritores contemporáneos Juan Villoro y Pablo Montoya. En Artes (artilugios) de Villoro, Miriam Gárate analiza varios de sus relatos y postula la incursión de otros lenguajes y otras lenguas como ejercicio exploratorio y productivo que Villoro utiliza para proponer una indagación desplazada (extraterritorial) de la cultura mexicana. Mónica Marinone (Los pintores de Montoya) examina Tríptico de la infamia (2014) y, superando el análisis anecdotario de las elecciones exóticas del colombiano (biografiar a tres pintores europeos protestantes del siglo XVI), postula que Montoya intenta "volvernos lectores-extranjeros":

Me refiero a cuando, en su juego de escribir el ver-mirar (de otros, propio), interfiere la significación —el dominio de la lengua y de los signos - y la significancia —el dominio de la pintura y el dibujo- hurgando en lo turbio [...], en el desborde que compone la mirada (de los otros), a través de su trabajo con la imaginación (p. 143).

Los cruces entre literatura y cine son explorados en la tercera parte del libro, en la cual Víctor Conenna y Eugenia Fernández indagan en la relación entre las artes, de la literatura al cine, en Treinta y ocho fronteras. De 'Gringo viejo a Old gringo' y del cine a la literatura, en Filmes 'entre paréntesis': Usos y abusos del cine en la escritura bolañiana. Conenna analiza el cruce de fronteras (territoriales, lingüísticas, temporales, oníricas, biológicas) representadas en la novela de Carlos Fuentes y en la adaptación fílmica de Luis Puenzo y Aida Bortnik; reconstruye las continuidades, mudanzas, alteraciones e innovaciones, haciendo hincapié en los procedimientos con los que el director y la guionista pretendieron mantener intactas la densidad e intensidad del texto y su dimensión dramática. Por su parte, Fernández estudia una zona no analizada de la producción de Roberto Bolaño, seleccionando algunos relatos compilados en el volumen póstumo Entreparéntesis. A partir de ellos, rastrea modos de leer de Bolaño y las operaciones que realiza sobre diversos materiales marginales (como el cine clase B o independiente), identificando la "reinvención" de dicho material cinematográfico y su trasformación en literatura a partir de sus "usos" y "abusos", y de la utilización de una lógica de escritura semiótica/disléxica alternativa. 
También la relación entre literatura y música tiene su propio espacio de reflexión; así, en la cuarta parte, los críticos que participan intentan superar la observación de lo meramente referencial para poner el foco en los procedimientos propios de la música con los que se construyen los textos de José Donoso, Chico Buarque y Tato Laviera. De este modo, Beethoven y Huxley contrapunteando 'El obscenopájaro de la noche', de Hortensia Morell identifica las alusiones intertextuales presentes en la novela de Donoso al Cuarteto 15, al Cuarteto para cuerdas en La menor y al Opus 132 de Beethoven y a Contrapunto de Aldous Huxley para proponer que la construcción musical contrapuntística es parte de la estructura de la novela. Desde una perspectiva más teórica, Hernán Morales (Chico Buarque entre lenguajes y lenguas: Una aproximación) recupera la figura de este escritor-músico para señalar cómo su proyecto de escritura trabaja con la sonoridad, lo que produce un grado de interferencia entre lenguajes que hacen de su narrativa una materialidad melopoética. Morales reflexiona sobre la literatura y la música convergiendo en dichos textos como códigos mediados por un continuum que se establece en modulaciones alcanzadas por la palabra escrita a partir de lo que denomina un desarrollo entonativo - el uso particular de los rasgos prosódicos tales como tonos, pausas, velocidad de habla, ritmo y altura tonal-, y por una disolución de categorías o fronteras que hacen de estos espacios narrativos, zonas materiales de desplazamiento entre lo diverso. Por su parte, Gabriela Tineo (Alalimón, voces negras) examina el poema Tesis de negreza de Tato Laviera desde un enfoque que privilegia el entretejido de lenguajes y voces como uno de los rasgos específicos de la poética del niuyorriqueño. Mediante inflexiones diversas que inscriben la canción popular El negro bembón, la crítica académica y la impostación individual o colectiva de un sujeto prieto, cuya voz se modula al ritmo del contrapunto o el acople con las otras voces, Tineo estudia cómo el poema interpela los discursos de la racialización, subrayando el juego donde voces, discursividades y lenguajes se mezclan y confrontan, permitiendo identificar el texto como un espacio de lucha.

La última parte del libro incluye estudios sobre la memoria y la traducción lingüístico-cultural del contexto caribeño insular. En El 'boom' de lo afro en la literatura. Creación y crítica en los últimos quince años, Silvia Valeropropone que desde el 2000 (cuando se instala el término "afrodescendiente" como denominador de un colectivo) se observa la presencia más marcada de subjetividades negras en la literatura latinoamericana y analiza los cruces e intercambios que el discurso del activismo negro y las ciencias sociales producen con ella, en particular en textos de Quince Duncan, Miguel Rosenzvit y Mirta Fachini. Alejandro Del Vecchio (Borges en clave cubana: El 'Alephengordante' de Ronaldo Menéndez") examina el cuento Menú insular del cubano, que traduce (en el sentido etimológico de "pasar de un lado a otro") El Aleph de Borges. Del Vecchio describe cómo la operatoria Menéndez contamina el universo literario borgeano para propiciar la reflexión y crítica de las condiciones de vida en la isla durante el "Período Especial"; de esta forma, el gesto subversivo no estaría dirigido contra el escritor argentino, sino orientado a profanar la palabra del gobierno revolucionario. Ana Sol Villarreal, en Dospoemas mixturaos, trabaja una selección del volumen Mixturao and other poems (2008), de Tato Laviera a partir de una categoría operatoria: la traducción considerada como traslación que implica el orden cultural y lingüístico. De acuerdo con esto, identifica el aspecto político relacionado con la práctica poética de Laviera y la construcción simbólica de un ámbito de reconocimiento colectivo entre fronteras.

Por último, el cierre del libro presenta el ensayo de Arcadio Díaz Quiñones, Once tesis sobre un crimen de 1899, quien analiza actas de juicios y testimonios de época para señalar las implicaciones políticas, jurídicas, sociales y culturales de un crimen ocurrido en Puerto Rico durante el cambio de siglo (XIX-XX), cuando se produce la ocupación militar de la isla por el ejército estadounidense; este hecho, le permite a Quiñones reflexionar de otro modo sobre el par imperialismo-cultura, la dominación negociada y su larga duración en el contexto puertorriqueño. 